\title{
Patentes, genéricos e acesso ao medicamento: o caso das pandemias
}

Patent rights, generic medicines and access to medicines: the case of pandemics

Patentes, genéricos y acceso a la medicina: el caso de las pandemias

Roberta S. M. Fernandes R. Marques ${ }^{1}$

\section{Resumo}

Este artigo tem por objetivo a realização de uma breve análise dos requisitos da patenteabilidade (novidade, atividade inventiva e aplicação industrial) e do procedimento de autorização de introdução do medicamento no mercado (AIM) no âmbito europeu e português, tendo em conta a atual crise pandêmica da COVID-19, bem como a possibilidade (ou não) de utilização da licença obrigatória em situações pandêmicas.

\section{Palavras-chave}

COVID-19. Vacinas. Patentes.

\begin{abstract}
This article aims to conduct a brief analysis of the requirements for patentability (novelty, inventive step and industrial application) and the authorization procedure for placing the medicine on the market in the European and Portuguese scope, taking into account the current crisis pandemic of COVID-19, as well as the possibility (or not) of using the mandatory license in pandemic situations.
\end{abstract}

\section{Keywords}

COVID-19. Vaccines. Patents.

\section{Resumen}

Este artículo tiene como objetivo realizar un breve análisis de los requisitos de patentabilidad (novedad, actividad inventiva y aplicación industrial) y el procedimiento de autorización para la comercialización del medicamento en el ámbito europeo y portugués, teniendo en cuenta la crisis actual. pandemia de COVID-19, así como la posibilidad (o no) de utilizar la licencia obligatoria en situaciones de pandemia.

\section{Palabras clave}

COVID-19. Vacunas. Patentes.

\section{Introdução}

A Organização Mundial de Saúde (OMS) (1) declarou, em meados de março de 2020 , que o surto do novo coronavírus atingiu o nível de pandemia. Desde então, acompanhamos estupefactos os hospitais com dificuldades para garantir o atendimento regular a pacientes devido a um aumento de casos de COVID-19, os profissionais de saúde e de manutenção dos hospitais exaustos e uma crise econômica e social sem precedentes.

\footnotetext{
${ }^{1}$ Professora adjunta convidada, Instituto Superior de Contabilidade e Administração de Coimbra (ISCAC) - Coimbra Business School, Departamento de Direito, Coimbra, Portugal. https://orcid.org/0000-0003-1382-7915. E-mail: rfernandes@iscac.pt
} 
As vacinas correspondem a uma esperança na volta da normalidade a que muitos países anseiam, bem como a identificação de um medicamento viável para o tratamento da COVID-19. No entanto, a introdução de uma vacina ou de um medicamento no mercado, bem como a alteração da indicação terapêutica não é tão simples como antecipam as notícias veiculadas acerca da matéria.

A Declaração da RedBioética da UNESCO recomenda que "as patentes farmacêuticas sejam suspensas durante a pandemia, com o objetivo de garantir que as populações mais vulneráveis sejam vacinadas e para evitar novas mutações" (2). Recomenda, ainda, que os Estados-membros da Organização Mundial do Comércio (OMC) prevejam exceções a determinadas obrigações constantes do Acordo TRIPS em relação à prevenção, à contenção e ao tratamento da COVID-19. Também, recomenda que as tecnologias de saúde para enfrentar a COVID-19 sejam bens públicos globais, livres de barreiras que imponham as patentes e/ou outros tipos de propriedade intelectual (2).

Ora, o acesso a uma vacina deveria ser, do ponto de vista moral, universal. Desta afirmação decorre uma pergunta: o acesso universal à vacina e/ou medicamento para o tratamento da COVID-19 poderia ser imposto à(s) farmacêutica(s) que a(s) desenvolveu(ram), à luz da legislação internacional e da legislação de cada um dos países onde fosse a mesma produzida, comercializada ou importada?

As empresas farmacêuticas e especialistas em saúde se esforçaram (e se esforçam) para encontrar uma vacina da COVID-19 e tratamentos viáveis, mas existem fatores que afetarão o desenvolvimento, a produção e a distribuição que devem ser levados em consideração. Um desses fatores é a propriedade industrial (proteção das vacinas através de patentes e de certificados complementares de proteção).

$\mathrm{A}(\mathrm{s})$ nova(s) vacina(s) ou mesmo um novo medicamento para o tratamento do vírus da COVID-19 será(ão) protegida(s) por uma patente por um prazo de 20 anos, nos termos do disposto no Acordo TRIPS, podendo este prazo de exclusividade merceológica ser superior, se for protegida por um certificado complementar de proteção (CCP).

Neste período de proteção patentária (ou CCP), o titular do direito teria a prerrogativa de explorar o seu invento com exclusividade (ou um licenciado do direito de exploração), uma vez que os direitos industriais são essencialmente direitos de utilização exclusiva, pois reservam aos titulares a exclusividade na exploração.

Um segundo fator é a regulação farmacêutica exercida pelas agências administrativas para introduzir a vacina e/ou medicamento no mercado, que na União Europeia é realizada 
pela Agência Europeia de Medicamento (EMA) (3) e em Portugal pela Autoridade Nacional do Medicamento e Produtos de Saúde (INFARMED) (4).

Tal se dá em razão da necessidade de averiguar a segurança do medicamento antes da sua comercialização, com o objetivo principal de proteger a saúde e a integridade do paciente/cidadão.

A regulação não está assente apenas na verificação da segurança do medicamento, através da concessão da autorização de introdução do medicamento (AIM), mas também na necessidade de fixação do preço de venda do medicamento, ou seja, as empresas farmacêuticas só poderão comercializar os seus produtos após o procedimento administrativo que irá determinar o valor máximo de venda do medicamento público.

Assim, o estudo está ordenado em duas partes. Na primeira parte, apresentar-se-á a patente farmacêutica - requisitos patentários (em Portugal e na União Europeia) -, bem como a diferença existente entre o medicamento de referência e o medicamento genérico, à luz do sistema regulatório farmacêutico, de forma abreviada, onde inclui-se a autorização de introdução do medicamento no mercado e a fixação do preço do medicamento.

Na segunda parte ver-se-á a solução existente no ordenamento jurídico internacional, europeu e português para o licenciamento da patente em caso de interesse público (licenças obrigatórias ou compulsórias), bem como apresentar-se-ão algumas ideias a problemas relacionados com a introdução do medicamento por via de uma licença obrigatória.

Não se pretende, com este trabalho, dar respostas definitivas à problemática analisada. Na verdade, o objetivo é suscitar as dúvidas, as indagações e os problemas que desafiam, não somente o direito português, como também os acordos no âmbito internacional. Finalmente, convém observar que, nas referências bibliográficas apresentadas ao final deste estudo, constam apenas as obras citadas no seu texto, embora outras não nominadas tenham concorrido para a formação do conjunto do trabalho.

\section{O direito de patentes de medicamentos}

A inovação farmacêutica é parte essencial dos esforços para conter a pandemia da COVID-19, sendo as vacinas e os medicamentos a maior esperança para que o mundo possa voltar à normalidade. Esse processo de inovação, no entanto, é muito complexo e dispendioso, fato que restringe o número de entes capacitados, técnica e financeiramente, para a busca exitosa de um novo medicamento ou de uma nova vacina. 
Após identificar um novo ingrediente ativo, um novo processo ou um novo uso, para a concessão da patente, é preciso verificar se preenche os requisitos da patenteabilidade. Assim, apenas podem ser objeto de patente as invenções novas, implicando atividade inventiva, se forem suscetíveis de aplicação industrial, incluindo invenções biotecnológicas, nos termos do art. 50. ${ }^{\circ}$, n. ${ }^{\circ} 1$, e do art. 53. ${ }^{\circ}$, n. ${ }^{\circ} 1, f$ do Código de Propriedade Industrial (CPI) (5).

Seguindo as diretrizes do art. $54 .^{\circ}$ da Convenção da Patente Europeia (CPE) (6), uma invenção "é considerada nova se não fizer parte do estado da técnica" (n. $\left.{ }^{0} 1\right)$. Este é "constituído por tudo o que foi tornado acessível ao público, antes da data da apresentação do pedido de patente europeia, por uma descrição escrita ou oral, uma utilização ou qualquer outro meio" (n. $\left.{ }^{\circ} 2\right)$. "É igualmente considerado como incluído no estado da técnica o conteúdo dos pedidos de patente europeia, tais como foram apresentados, que têm uma data de apresentação anterior à mencionada no $n .^{\circ} 2$ e que não foram publicados a não ser nessa data ou em data posterior" (n. ${ }^{\circ} 3$ ). Em sentido próximo, dispõem o n. ${ }^{\circ} 1$ do art. $54 .^{\circ} \mathrm{e}$ o n. ${ }^{\circ} 1$ do art. $55 . .^{\circ}$ do CPI.

Registre-se, no entanto, que podem ser obtidas patentes para quaisquer invenções, quer se trate de produtos ou de processos, em todos os domínios da tecnologia, conforme prevê o n. $^{\circ} 2$ do art. $50 .{ }^{\circ}$ do CPI. Também, nos termos do n. ${ }^{\circ} 3$ do referido artigo, "podem igualmente ser objecto de patente os processos novos de obtenção de produtos, substâncias ou composições já conhecidos".

Ou seja, é possível haver novidade em um produto (substância ou composição) já compreendido no estado da técnica, para aplicação em um método de diagnóstico e tratamento.

Acerca da atividade inventiva, a CPE define seus requisitos no art. $56 .^{\circ}$, estipulando que "uma invenção é considerada como envolvendo actividade inventiva se, para um perito na técnica, não resultar de uma maneira evidente do estado da técnica".

O estado da técnica é definido pelo n. ${ }^{\circ} 2$ do art. $54 .^{\circ}$ da CPE, que trata da novidade. Assim, em razão da expressa remissão ao n. ${ }^{\circ} 3$ do art. $54 .{ }^{\circ}$ da Convenção, para a verificação do nível inventivo junto ao Instituto Europeu de Patentes (IEP) não se devem levar em apreço os pedidos de patente anteriores ainda não divulgados. Isto demonstra que o estado da técnica utilizado na avaliação da atividade inventiva é mais restrito do que aquele utilizado no exame da novidade, que considera tais anterioridades. Em Portugal, o requisito da 
atividade inventiva está previsto no $n .^{\circ} 2$, do art. $54 .^{\circ}$ do $\mathrm{CPI}$, e o conteúdo do estado da técnica no art. $55^{\circ}$.

E, por fim, a invenção tem que ser dotada de aplicação industrial, ou seja, a regra técnica inerente à invenção tem que ser executável na prática, reprodutível: o resultado inventivo não pode depender da álea, do destino ou de condições não controláveis tecnicamente pelas pessoas (vide art. $57 .^{\circ}$ da $\mathrm{CPE}$ e art. $54 .^{\circ}, \mathrm{n} .{ }^{\circ} 4$ do $\mathrm{CPI}$ ).

Assim, pela legislação europeia (e portuguesa) pode-se obter a patente de um novo produto, a exemplo de uma vacina (AstraZeneca, Pfizer, Moderna, Oxford, etc.), do processo para se obter a vacina (modo para alcançar o produto) e de um novo uso de um ingrediente ativo ou medicamento já conhecido (a exemplo do Remdesivir).

O medicamento Remdesivir é protegido pelas patentes europeias n. ${ }^{\circ} 3366295$ (métodos de tratamento de infeções pelo vírus filoviridae) e n. ${ }^{\circ} 3212174$ (métodos para o tratamento de infecções pelo vírus filoviridae) (7) até o ano de 2035 (8). Este medicamento obteve uma autorização de introdução no mercado sob reserva, à luz do art. $22 .^{\circ}$ da Diretiva n. ${ }^{\circ}$ 2001/83/CE do Parlamento Europeu e do Conselho, para o tratamento da COVID-19.

Assim, para ser produzido e/ou comercializado será necessária a autorização do titular da patente, in casu, a Gilead Sciences, Inc., sob pena de infração ao direito de utilização exclusiva prevista na proteção patentária.

Ou seja, em teoria seria possível obter a patente de segundo uso de um medicamento para um outro tratamento médico, desde que presentes os requisitos da patenteabilidade e respeitados os direitos de propriedade industrial do titular da patente.

Por fim, é de acrescentar que existe um mecanismo de prorrogação do prazo de duração da patente, denominado certificado complementar de proteção, regulado nos arts. $116 .^{\circ}$ a $117 .^{\circ}$ do CPI e no Regulamento (CEE) n. ${ }^{\circ}$ 1786/92 (9) (para produtos farmacêuticos e fitofarmacêuticos).

\section{Medicamentos de referência}

O medicamento de referência é o produto inovador registrado no órgão responsável pela vigilância sanitária e comercializado no país ou nos países que façam parte da União Europeia, cuja eficácia, segurança e qualidade foram comprovadas cientificamente junto ao órgão administrativo competente, por ocasião do registro. Normalmente corresponde ao medicamento patentado. 
O medicamento patenteado, antes de ser comercializado, necessita de uma autorização de comercialização (AIM) outorgada por uma agência (em Portugal, a concessão da AIM cabe ao INFARMED) distinta dos institutos de patentes, que baseará sua decisão em critérios de segurança, eficácia e qualidade. Para tanto, a empresa solicitante obriga-se a realizar testes farmacológicos, toxicológicos, pré-clínicos e clínicos da nova entidade química ou das novas aplicações terapêuticas. A finalidade é garantir a segurança do cidadão e proteger a sociedade de medicamentos nocivos ou ineficazes.

A regulamentação referente à comercialização dos medicamentos para uso humano na União Europeia foi compilada por meio da Diretiva $n .^{\circ}$ 2001/83/CE, que estabeleceu um Código Comunitário relativo aos medicamentos para uso humano, vindo depois a ser objeto de alteração pela Diretiva n. ${ }^{\circ}$ 2004/27/CE do Parlamento e do Conselho. Também é regulada pelo Regulamento (CE) n. ${ }^{\circ}$ 726/2004, alterado pelo Regulamento (UE) n. ${ }^{\circ}$ 1027/2012 do Parlamento Europeu e do Conselho de 25 de outubro de 2012, que estabeleceu procedimentos comunitários de autorização e de fiscalização de medicamentos para uso humano e veterinário e que instituiu a Agência Europeia de Medicamento.

A solicitação de autorização de introdução do medicamento (AIM) no âmbito da União Europeia pode ser realizada por quatro tipos de procedimentos: centralizado, de reconhecimento mútuo, descentralizado e nacional. Pelo procedimento centralizado, requerido junto a Agência Europeia de Medicamento (EMEA), a AIM é válida em todos os Estados-Membros da União Europeia. O procedimento centralizado é obrigatório para os medicamentos que incluem substâncias ativas em seis áreas terapêuticas diferentes, a saber: HIVISIDA, diabetes, câncer, doenças neurodegenerativas, medicamentos-órfãos e produtos biotecnológicos.

$\mathrm{Na}$ União Europeia, os medicamentos de referência correspondem àqueles cuja comercialização foi autorizada com base na documentação completa (farmacêuticos: físicoquímicos, biológicos ou microbiológicos; pré-clínicos 'toxicológicos e farmacológicos'; e clínicos), conforme dispõem o art. 8. ${ }^{\circ}$, n. $^{\circ} 3$, alínea $i$, da Diretiva n. ${ }^{\circ}$ 2001/83/CE do Parlamento Europeu e do Conselho, de 06 de novembro de 2001 (e demais alterações), e do art. 6. ${ }^{\circ}, \mathrm{n},{ }^{\circ} 1$ (10), do Regulamento (CE) n. ${ }^{\circ} 726 / 2004$, do Parlamento Europeu e do Conselho, de 21 de março de 2004. No mesmo sentido, estabelece a legislação portuguesa, conforme explicitado no art. $3^{\circ}$, n. $^{\circ} 1$, alínea ii, do Decreto-Lei n. ${ }^{\circ}$ 176/2006.

Por sua vez, em Portugal, no caso dos medicamentos de referência, o pedido de aprovação e registro (AIM) é acompanhado de todos os resultados de ensaios 
farmacêuticos, pré-clínicos e clínicos, bem como de todas as informações relevantes para a avaliação do medicamento em questão. É o que se observa da leitura do Estatuto do Medicamento (Decreto-Lei n. ${ }^{0}$ 176/2006), que prevê a obrigatoriedade da realização de ensaios farmacêuticos, pré-clínicos e clínicos na alínea j, do n. 2 do art. $15 .^{\circ}$.

Ou seja, para o medicamento de referência (novo/patentado) ser comercializado é preciso apresentar a documentação completa dos testes realizados junto à EMA ou ao INFARMED, caso a solicitação seja feita aqui em Portugal.

No entanto, é possível, em situações excecionais, como a que estamos a vivenciar (pandemia da COVID-19) utilizar um mecanismo excecional, mais célere, previso no art. $14{ }^{\circ}$ e no art. $14 .^{\circ}-A$ do Regulamento (CE) n. ${ }^{\circ} 726 / 2004$ e no art. $22 .^{\circ}$ e ss. da Diretiva n. ${ }^{\circ}$ 2001/83/CE do Parlamento Europeu e do Conselho, de 06 de novembro de 2001 (e demais alterações) (11).

As vacinas que foram objeto de pedido(s) e/ou autorização(ões) pela EMA até a presente data utilizaram esse mecanismo excecional, a exemplo da Corminaty (BioNTech, Fosun Pharma, Pfizer) (12), da COVID-19 Vaccine AstraZeneca (13) e da COVID-19 mRNA Vaccine nucleoside modified (Moderna) (14).

\section{Medicamentos genéricos}

Os medicamentos genéricos, na União Europeia, são os que apresentam a mesma composição qualitativa e quantitativa em substâncias ativas, sob a mesma forma farmacêutica, cuja bioequivalência em relação aos medicamentos de referência tenha sido demonstrada através de estudos de biodisponibilidade adequados, nos termos do disposto no $n .^{\circ} 2$, alínea $b$, do art. $10 .^{\circ}$ da Diretiva $n .^{\circ} 2001 / 83 / C E$, conforme redação da Diretiva $n .^{\circ}$ 2004/27/CE. Em Portugal, nos mesmos termos, a alínea $v v$ do n. ${ }^{\circ} 1$ do art. $3 .^{\circ}$ do DecretoLei n. ${ }^{\circ}$ 176, de 30 de agosto de 2006 (e alterações subsequentes) (15).

Portanto, na essência do seu conceito, o medicamento genérico é aquele que contém o mesmo princípio ativo do medicamento de referência anteriormente aprovado no país. Além disso, deve apresentar a mesma segurança, devidamente comprovada através de testes de bioequivalência, biodisponibilidade, intercambialidade e equivalência terapêutica. Esses testes deverão ser desenvolvidos de acordo com as regras previstas pela boa prática farmacêutica, com o intuito de facilitar o atendimento dos requisitos para a obtenção da autorização de introdução no mercado (AIM) e viabilizar a apresentação de um quadro das diferenças entre esse tipo de medicamento e o medicamento de referência. 
Para o medicamento genérico ser aprovado é preciso, apenas, provar que possui bioequivalência (parâmetros farmacocinéticos - curva de concentração tempo AUC e concentração plasmática (Cmax); equivalência terapêutica; intercambialidade (permutabilidade e substituibilidade) e biodisponibilidade.

A empresa, entretanto, será dispensada de apresentar o resultado dos ensaios clínicos se comprovar tratar-se de um medicamento genérico de um medicamento de referência, que tenha sido autorizada a sua comercialização há, pelo menos 8 anos, num dos Estados membros ou na UE (Decreto-Lei n. ${ }^{\circ} 176 . \% / 2006$, art. $19 .^{\circ}, \mathrm{n} .^{\circ} 1$ ).

Por fim, deve-se esclarecer que os dados apresentados para a obtenção da AIM podem ser protegidos ( 8 anos +2 anos +1 ano). Esta proteção consta da Diretiva $n \cdot{ }^{\circ} 2001 / 83$ com a redação da Diretiva $n .^{\circ}$ 2004/27/CE, do art. $14 .^{\circ}$ do Regulamento (CE) n. ${ }^{\circ} 726 / 2004$ e dos arts. $15 .^{\circ},{ }^{\circ}{ }^{\circ} 2$, "r", $19 .^{\circ},{ }^{\circ}{ }^{\circ} 1$, e $22 .^{\circ}$ do Decreto-Lei n. ${ }^{\circ} 176 / 2006$.

Além da autorização administrativa (AIM) perante o INFARMED, em Portugal, antes de o medicamento ser lançado no mercado, é imprescindível a fixação pela entidade administrativa do preço máximo de venda do produto ao público. A competência é do INFARMED, nos termos do disposto no art. $8^{\circ}$ do Decreto-Lei n. ${ }^{\circ}$ 97/2015, de 1 de junho (16).

\section{A possibilidade de licença obrigatória para a produção de vacinas (?)}

O reconhecimento do direito de exclusividade (direito patentário) - autêntico monopólio legal - tem por fim precípuo o interesse público. Para coibir abusos porventura praticados pelos titulares desse direito e salvaguardar direitos da sociedade, em situações excecionais (como em uma pandemia), são previstas salvaguardas legais (a exemplo da exaustão de direitos, da importação paralela, da licença compulsória, entre outras). As licenças obrigatórias ou compulsórias representam as mais importantes dessas salvaguardas, na medida em que se concretizam como uma limitação ao direito decorrente das patentes (17). Em sua essência, consistem na permissão de industrialização e comercialização de um produto patenteado, sem o consentimento do titular do monopólio, sempre que o interesse público o exigir.

O acordo TRIPS, no seu n..$^{\circ} 1$ do art. $8 .^{\circ}$ estabelece, como um dos seus princípios básicos, que os Estados contratantes, no exercício das suas tarefas legiferantes, podem adotar medidas necessárias para proteger a saúde e nutrição públicas e para promover o interesse público em setores de importância vital para o seu desenvolvimento sócio- 
económico e tecnológico, desde que estas medidas sejam compatíveis com o disposto neste Acordo.

Relativamente à licença compulsória ou obrigatória, embora o Acordo TRIPS (22) não a tenha mencionado expressamente em seu texto, os arts. $30 .^{\circ}$ e $31 .^{\circ}$ preveem uma permissão que, implicitamente, nada mais é que a própria exceção. Entre os requisitos elencados no art. $31 .^{\circ}$ para esse regime excecional, destacam-se os seguintes: i) o interessado deve previamente buscar obter autorização do titular, em termos e condições comerciais razoáveis, e que esses esforços não tenham sido bem sucedidos num prazo razoável, exigência essa que pode ser dispensada em caso de urgência e emergência nacional; ii) o pedido de licença deve ser analisado em seus méritos individuais; iii) o alcance e a duração desse uso excepcional devem circunscrever-se ao objetivo para o qual foi autorizado; iv) esse uso deve ser não-exclusivo; v) o titular deve ser adequadamente remunerado nas circunstâncias de cada uso (18) (19).

A preocupação com o acesso da população a medicamentos foi motivo de uma pauta de debates específica na OMC, que culminou com a Declaração de Doha, de 20 de setembro de 2001. Nessa Declaração foi ressaltada a importância que o Acordo TRIPS tem em questões relacionadas à saúde pública e na promoção do acesso aos medicamentos (20).

No documento, ficou convencionado que o Acordo TRIPS não podia nem devia impedir que os membros adotassem medidas com o objetivo de promover a saúde pública. Estabeleceu-se, também, que estes podiam fazer uso das flexibilidades previstas, em particular das licenças compulsórias e das importações paralelas.

Ainda assim, uma questão ficou pendente, qual seja, de como os países que não possuíam capacidade para industrializar os produtos farmacêuticos poderiam obter medicamentos genéricos fabricados ao amparo das licenças compulsórias, sem descumprir a letra $f$ do art. 31 do Acordo TRIPS. A questão foi aparentemente superada em 30 de agosto de 2003, quando se chegou a um acordo sobre as modificações regulamentares. Com isso, os países que não tinham condições de fabricar os medicamentos foram autorizados a importar genéricos mais baratos fabricados ao amparo das licenças compulsórias de outros países-membros. Essa solução foi aparente, porque ficou longe de atingir os fins colimados, principalmente no que concerne à sua exeqüibilidade, embora teoricamente abrangida pelas medidas propostas no texto do acordo. E é exatamente esta burocracia que pode retardar o acesso às vacinas da COVID-19. 
A decisão exime os países exportadores de suas obrigações previstas na letra $f$ do art. 31. Dessa forma, qualquer país-membro pode exportar produtos farmacêuticos genéricos fabricados ao amparo de licenças obrigatórias para atender as necessidades dos países importadores, desde que observadas as condições estabelecidas no seu texto.

O procedimento estabelecido pela Decisão de Cancun a ser observado pelos países que pretendem importar um medicamento genérico é demorado e burocrático, iniciando-se com três notificações ao Conselho do Acordo TRIPS. Primeiramente, o país interessado deve enviar uma notificação geral acerca de sua intenção de se qualificar como país-membro importador (exigência não aplicável a países menos desenvolvidos). Em seguida, deve encaminhar uma segunda notificação, de caráter específico, fixando: a) os nomes dos produtos a serem importados (nomes genéricos); b) as quantidades consideradas necessárias para uso local; c) declaração de falta ou de insuficiência de capacidade de produção local.

Esta última exigência pode ser estabelecida com base em duas condições: a) quando o país não possui qualquer capacidade de produção na área farmacêutica; b) quando o país possui capacidade de produção na área farmacêutica, mas essa capacidade foi eliminada pelo detentor local da patente ou por seu licenciado. Por fim, quando o produto farmacêutico for patenteado no território de importação, o país importador deverá notificar o Conselho do Acordo TRIPS sobre sua intenção ou sobre a efetiva concessão de uma licença compulsória (21).

A Decisão não inova no que diz respeito aos pressupostos para a concessão de licenças compulsórias, exigindo apenas que a licença compulsória seja concedida dentro das condições estabelecidas no art. 31 do Acordo TRIPS. Porém, não exige que o licenciado no país importador pague royalties ao titular da patente local. A princípio, a compensação deverá ser paga apenas no país exportador. Isso dependerá sempre do modo como os países implementarão, internamente, essa Decisão. As três notificações referidas anteriormente objetivam dar transparência ao sistema, tendo efeito meramente declaratório. Significa que não se exige qualquer autorização/aprovação da OMC para uso do sistema. Uma vez encaminhadas as notificações, os países estarão automaticamente autorizados a fazer uso do sistema.

O procedimento a ser observado pelo país exportador é igualmente burocrático. A empresa que pretenda exportar, deve, primeiramente, procurar negociar com o titular da patente a concessão de uma licença voluntária em termos comercialmente razoáveis. No 
entanto, a Decisão exige que seja preservado o direito do titular da patente em recorrer da decisão das autoridades que concederem a licença compulsória. Mas, ao implementar essas normas, o Estado deve considerar o efeito do recurso administrativo ou judicial. Nesse caso, entendemos que a melhor solução seja a de impetrar recursos com efeito não-suspensivo.

Em resumo, com base nos dispositivos constantes da Decisão, o país importador que desejar utilizar o sistema deverá notificar a OMC quanto ao seu propósito de adquirir os produtos de um país exportador. Trata-se, nesse caso, de um país que utilize o sistema, com o objetivo de produzir produtos farmacêuticos para um membro importador habilitado e exportá-los para aquele país.

Assim, em observância aos termos do estatuído na Decisão, o país exportador se eximirá do cumprimento das obrigações constantes na letra $f$ do art. 31 do Acordo TRIPS. Essa liberação diz respeito à concessão por esse membro de uma licença obrigatória, na medida necessária para a produção de um produto farmacêutico e sua exportação a um membro importador habilitado. Ou seja, tanto o membro importador como o exportador deverão expedir licenças obrigatórias, sendo uma destinada à importação e outra à exportação. Não obstante, o membro exportador só poderá fabricar o produto, ao amparo da licença, na quantidade suficiente para satisfazer as necessidades do membro importador habilitado através de notificação.

Em Portugal, o CPI prevê, no $n .^{\circ} 2$ do art. $111 .^{\circ}$, a possibilidade de concessão de licença obrigatória por motivo de interesse público, no caso da emergência de graves problemas de saúde pública, com vista à tutela da saúde pública. No entanto, se colocam alguns entraves à aplicabilidade prática de tal mecanismo, uma vez que, em sede de situações pandêmicas ou epidêmicas, pode não existir, ainda, uma patente concedida para a vacina e/ou medicamento.

Mas como seria possível a obtenção de uma licença obrigatória sem existir uma prévia patente registrada (e concedida) pelo INPI? As vacinas ou medicamentos inovadores para o tratamento da COVID-19 provavelmente não são objeto de direito de patente (ou CCP) quando a administração pública mais necessita a sua utilização.

O CPI português prevê vários tipos de licenças obrigatórias no art. ${ }^{\circ} 108 .^{\circ}$ e ss. Algumas são requeridas e concedidas pelo INPI e são precedidas de um procedimento administrativo contraditório com a intervenção do titular da patente, sendo que da decisão do INPI (ato administrativo) caberá recurso para o Tribunal da Propriedade Intelectual (TPI), 
embora o montante da compensação e as condições da licença sejam suscetíveis de recurso judicial ou arbitral (art. $108 .^{\circ}, \mathrm{n} .^{\circ} 7$ do $\left.\mathrm{CPI}\right)$.

As que nos interessam, que prevêem as situações de interesse público (em rigor, a saúde pública e a defesa nacional), são emitidas pelo membro do Governo competente em razão da matéria (pelo Ministro da Saúde ou da Defesa), nos termos do n. ${ }^{\circ} 4$ do art. $111 .^{\circ}$ e, ao que nos parece, não estão sujeitas ao procedimento administrativo acima referido.

No entanto, tal pode ser questionado, em razão da norma constante no n. ${ }^{\circ} 3$ do art. 108. ${ }^{\circ}$ do mesmo CPI, ao determinar que "as licenças obrigatórias só podem ser concedidas quando o potencial licenciado tiver desenvolvido esforços no sentido de obter do titular da patente uma licença contratual em condições comerciais aceitáveis e tais esforços não tenham êxito dentro de um prazo razoável".

Preveem-se, ademais, as licenças obrigatórias para fins de fabrico e exportação de medicamentos para países com graves problemas de saúde pública, ao abrigo do Regulamento (CE) n. ${ }^{\circ}$ 816/2006 (22). Em todos estes casos, o legislador parte do pressuposto de que a patente (ou CCP) já foram concedidos, não abrangendo, ao que tudo indica, os direitos decorrentes de pedidos de patente (ou CCP), ao contrário do que ocorre com as licenças voluntárias, as quais podem ser negociadas e concedidas relativamente aos direitos emergentes de pedidos de patente (ou CCP), nos termos do $n .^{\circ} 2$ do art. $31 .^{\circ}$ do $\mathrm{CPI}$ (23) (24).

O regime da emissão de licenças obrigatórias de direitos de patente por motivos de interesse público deve ser apenas usado em situações excecionais, caso não seja possível chegar a um acordo com o titular da patente. No entanto, a eventual emissão de tais licenças deve ser acompanhada da remoção de obstáculos na utilização dos dados pré-clínicos e clínicos concernentes a medicamentos de referência e à suspensão dos efeitos decorrentes dos direitos exclusivos de comercialização que aproveitam aos titulares de autorizações de introdução no mercado de medicamentos de referência, sob pena de inviabilizar, na prática, a utilização do produto e/ou processo patenteado objeto da licença compulsória.

\section{Outras soluções/problemas relacionados à introdução de um medicamento por via de licença obrigatória}

A possibilidade de os Governos e as autoridades terem acesso imediato às cadeias de fabricação e introdução no mercado de medicamentos, outros dispositivos e substâncias, para além das soluções, também excecionais, da emissão de licenças obrigatórias ou 
compulsórias de direitos de patente (e CCP), em caso de epidemias e pandemias constituiu uma preocupação de alguns Estados mais desenvolvidos logo após a declaração da epidemia da COVID-19, no início de março de 2020, por parte da OMS.

Como já analisado, a preocupação com o acesso da população a medicamentos foi motivo de uma pauta de debates específica na OMC, que culminou com a Declaração de Doha, de 20 de setembro de 2001 e na Resolução de 2003. Na referida Declaração foi ressaltada a importância que o Acordo TRIPS tem em questões relacionadas à saúde pública e na promoção do acesso aos medicamentos. No entanto, pese embora contemple a possibilidade do licenciamento compulsório até nas situações em que o país não tenha condições de produção própria do medicamento/vacina, através da importação, o mecanismo é demasiado burocrático. A sugestão é que o mesmo seja revisto para viabilizar a flexibilização em situações pandêmicas, como a atual (21).

Perante a situação de pandemia declarada por causa da COVID-19, a Alemanha foi dos primeiros Estados a operar esta possibilidade, com a Gesetz aur Verhütung und Bekämpfung von Infektionskrankheiten beim Menschen - Infektionsschutzgesetz - IfSG, em finais de março de 2020 (25). Isto, igualmente, em relação à criação de um regime excecional de emissão de licenças compulsórias de direitos de patente e modelos de utilidade.

O mesmo ocorreu em França. A Lei n. ${ }^{\circ}$ 2020-290, de 23 de março de 2020, alterou o art. 3131-15 do Code de la Santé Publique. Doravante, o Primeiro-Ministro francês pode, quando for declarado um estado de emergência sanitária e com o único propósito de garantir a saúde pública, determinar a prática dos seguintes atos: "ordenar a requisição de qualquer pessoa e de todos os bens e serviços necessários ao combate à catástrofe sanitária" e "tomar todas as medidas para disponibilizar aos pacientes medicamentos adequados para a erradicação da catástrofe sanitária".

As medidas prescritas devem ser estritamente proporcionais aos riscos para a saúde incorridos e adequadas às circunstâncias de tempo e lugar. Por outro lado, estatui-se que o cômputo da compensação devida ao titular é regido Code de la Défense (26). Claramente, essas medidas extraordinárias do legislador francês visaram flexibilizar o regime do licenciamento ex officio para adaptá-lo às circunstâncias de extrema emergência da pandemia da COVID-19.

Isto porque os arts. L. 613-16 e ss. do Code de la Propriété Intellectuelle não são suficientemente elásticos para permitir, num curto espaço de tempo, a prática dos referidos atos por parte da Administração Pública francesa (27). 
Em Israel, o Governo, sob parecer da Procuradoria-Geral da República, emitiu uma licença obrigatória, ao abrigo das Secções 104 e 105 da Lei de patentes deste país, de 1967, relativa ao medicamento antirretroviral denominado Kaletra, no tratamento da COVID-19 (lopinavir/ritonavir), pela qual o Governo arroga-se no poder de produzir e usar esse medicamento ou autorizar que terceiros o produzam e distribuam (23).

O Canadá, em 25 de março de 2020, também aprovou inúmeras medidas de combate à COVID-19, de entre as quais se inclui a compressão de direitos de patente por via da possibilidade de emissão de licenças obrigatórias com dispensa de negociação prévia entre o titular e a entidade interessada em utilizar o objeto da invenção. No que tange à possibilidade de emissão imediata e ex officio de licenças obrigatórias intransmissíveis, por motivo de situações de calamidade em matéria de saúde pública, a pedido do Ministério da Saúde, em regra, com a duração máxima de um ano, sendo o titular notificado em momento, a fim de ser iniciado o procedimento de fixação da compensação (28).

Em Portugal, em razão do regime da emissão de licenças obrigatórias de direitos de patente por motivos de interesse público, deve ser apenas usado in extremis, se e quando outras medidas menos intrusivas não forem cabíveis.

Também, o regime português pressupõe a concessão dos direitos de patente. No entanto, para ter efeitos práticos, o pedido de concessão e a eventual emissão de tais licenças deve ser acompanhada da remoção de obstáculos na utilização dos dados farmacológicos, pré-clínicos e clínicos respeitantes a medicamentos de referência (AIM) e à suspensão dos efeitos decorrentes dos direitos exclusivos de comercialização que aproveitam aos titulares de autorizações de introdução no mercado de medicamentos de referência.

Ora, para viabilizar tal medida, seria necessário efetuar uma alteração à Lei que institui o sistema de vigilância em saúde pública (art $17 .^{\circ}$ da Lei $n .^{\circ} 81 / 2009$ ), no sentido de ser possível (num horizonte temporal previamente determinado), mediante despacho (ato administrativo) do Ministério da Saúde (ou, de forma mais solene e colegial, por meio de Resolução do Conselho de Ministros) assegurar o fornecimento imediato das substancias ativas, materiais de partida, excipientes, adjuvantes, matérias-primas, gases medicinais, dispositivos médicos, máquinas, maquinismos, métodos e kits de diagnóstico, bem como equipamentos de proteção individual e desinfetantes. Também, deve operar a suspensão do prazo de proteção dos dados de testes e os efeitos decorrentes dos direitos exclusivos de comercialização, a fim de permitir a introdução no mercado de medicamentos genéricos num 
curto espaço temporal, se for caso disso e dos demais dispositivos médicos, máquinas, maquinismos, etc. (23).

Seria um procedimento administrativo cuja iniciativa nasceria ex officio no Ministério da tutela, no caso no Ministério da Saúde, o qual culminaria com um ou vários atos administrativos pelos quais se operaria a requisição de bens (móveis) ou direitos relativos aos direitos de propriedade industrial envolvidos, incluindo os direitos emergentes dos pedidos de patente, e dos direitos exclusivos de comercialização.

Isto porque o medicamento em causa (uma vacina) pode achar-se protegida por vários direitos de patente (ex. das substâncias intermediárias, dos materiais de partida, do(s) processo(s) de síntese química ou biotecnológica, da formulação farmacêutica, etc.), os quais, por força da observância do princípio da unidade da invenção (art. $73 .^{\circ}$ do CPI), foram objeto de vários pedidos ou de pedidos divisionários.

Pelo que, também estaria incluído o acesso aos dossiê clínico completo apresentado para a obtenção da AIM do medicamento de referência ou à eventual autorização excecional que já tivesse sido emitida pelo INFARMED, bem como ocorreria a suspensão da tutela dos dados de testes e ensaios, permitindo-se que o Governo, através do INFARMED, pudesse usar o referido dossiê de aprovação sanitária para autorizar o fabrico, a importação ou a comercialização de medicamentos genéricos ou, ele próprio, fabricar e distribuir tais medicamentos através dos órgãos da Administração Pública direta ou indireta. Evidentemente, deverá ficar garantido que o INFARMED e as demais entidades envolvidas (incluindo o licenciado) asseguram a proteção dessas informações contra a concorrência desleal e as práticas comerciais desonestas ou desleais (23).

Ademais, deverá salientar-se que a concessão da licença obrigatória nos moldes atrás sugeridos não deverá depender da constatação de que o titular da patente, certificado complementar de proteção ou do pedido de patente, diretamente ou por intermédio de licenciado, não atende às necessidades decorrentes da situação de emergência de saúde pública.

Por outro lado, o titular das patentes ou pedido de patente objeto de licenciamento obrigatório deverá ter o ônus de disponibilizar às entidades administrativas competentes (ou ao licenciado) todas as informações necessárias e suficientes à efetiva reprodução dos objetos protegidos.

Com efeito, não podemos esquecer que, na ausência de direitos de patente concedidos a medicamentos (ou composições ou formulações farmacêuticas ou vacinas) 


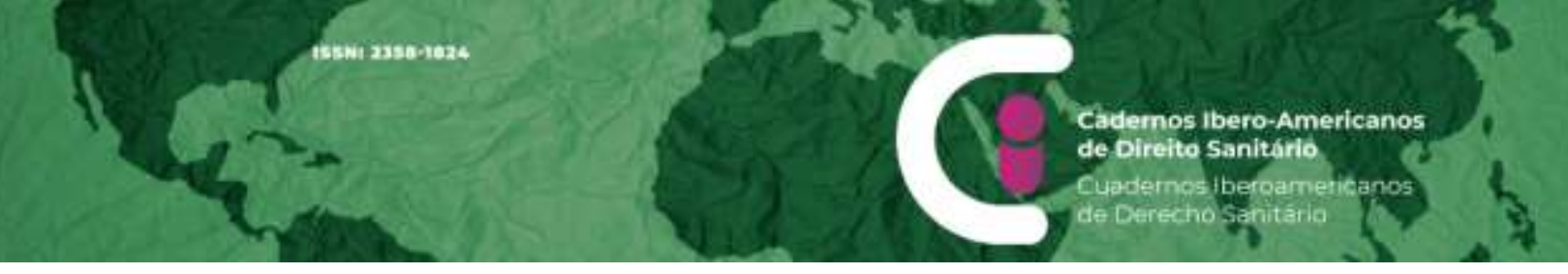

para combater epidemiais ou pandemias, o poder executivo deve premunir-se de instrumentos jurídicos suscetíveis de operar a suspensão dos efeitos decorrentes do prazo de proteção dos dados respeitantes aos ensaios pré-clínicos e clínicos e os efeitos decorrentes dos direitos exclusivos de comercialização referentes a medicamentos de referência previstos nos $n .^{\circ}$ s 1,3 e 7 do art. $19 .^{\circ}$ do Decreto-Lei n. ${ }^{\circ}$ 176/2006, de modo a poder fixar, num curto espaço de tempo, os termos da utilização dos dados de testes e a comercialização dos medicamentos, incluindo a fixação do preço e a margem de comparticipação (23).

\section{Referências}

1. World Health Organization (WHO). WHO Director-General's opening remarks at the media briefing on COVID-19 - 11 March 2020. [citado em 10.fev.2021]. Disponível em: https://www.who.int/director-general/speeches/detail/who-director-general-s-openingremarks-at-the-media-briefing-on-covid-19---11-march-2020

2. Organização das Nações Unidas para a Educação, a Ciência e a Cultura (UNESCO). Declaración de la Redbioética UNESCO. [citado em 12.fev.2021]. Disponível: https://redbioetica.com.ar/las-vacunas-deben-ser-un-bien-publico-de-la-humanidad/

3. Portugal. Autoridade Nacional do Medicamento e Produtos de Saúde, I.P. O INFARMED. [citado em 16.fev.2021]. Disponível em: https://www.infarmed.pt/

4. Holanda. Agência Europeia de Medicamentos (EMA). [citado em 12.fev.2021].

Disponível em: https://www.ema.europa.eu/en

5. Portugal. Decreto-lei n. ${ }^{\circ} 110 / 2018$, de 10 de dezembro. Portugal. [citado em 5.fev.2021]. Disponível em: https://dre.pt/home/-/dre/117279933/details/maximized

6. Munique. Convenção da Patente Europeia (CPE). [citado em 5.fev.2021]. Disponível em: https://www.epo.org/law-practice/legal-texts/epc.html

7. Portugal. Instituto Nacional de Propriedade Industrial (INPI). Patente Europeia n. ${ }^{\circ}$ 3212174 [citado em 5.fev.2021]. Disponível em:

https://servicosonline.inpi.justica.gov.pt/pesquisas/GetSintesePDF?nord=6430250

8. Portugal. Instituto Nacional de Propriedade Industrial (INPI). [citado em 5.fev.2021]. Disponível em:

https://pt.espacenet.com/publicationDetails/biblio?DB=EPODOC\&II=0\&ND=3\&adjacent=tru $\underline{\mathrm{e} \&}$

9. União Europeia. Regulamento (CEE) n. ${ }^{\circ}$ 1786/92, de 9 de junho de 1986. [citado em 10.fev.2021]. Disponível em: https://eur-lex.europa.eu/legalcontent/PT/TXT/PDF/?uri=CELEX:31986R1786\&from=ET 
10. União Europeia. Regulamento (CE) n. ${ }^{\circ}$ 726/2004, de 31 de março de 2004. [citado em 7.fev.2021]. Disponível em: https://eur-lex.europa.eu/legal-

content/PT/TXT/?uri=celex\%3A32004R0726

11. União Europeia. Diretiva $n .{ }^{\circ} 2001 / 83$, de 6 de novembro de 2001. [citado em 7.fev.2021]. Disponível em: https://eur-lex.europa.eu/legalcontent/PT/TXT/?uri=celex:32001L0083

12. Holanda. Agência Europeia de Medicamentos (EMA). Resumo das Características do Medicamento [citado em 10.fev.2021]. Disponível em:

https://www.ema.europa.eu/en/documents/product-information/comirnaty-epar-productinformation pt.pdf

13. Holanda. Agência Europeia de Medicamentos (EMA). COVID-19 Vaccine AstraZeneca. [citado em 10.fev.2021]. Disponível em: https://www.ema.europa.eu/en/documents/productinformation/covid-19-vaccine-astrazeneca-product-information-approved-chmp-29-january2021-pending-endorsement en.pdf

14. Holanda. Agência Europeia de Medicamentos (EMA). Spikevax (vacina ARNm contra a COVID-19 [nucleósido modificado]). [citado em 10.fev.2021]. Disponível em:

https://www.ema.europa.eu/en/documents/overview/spikevax-previously-covid-19-vaccinemoderna-epar-medicine-overview pt.pdf

15. Portugal. Decreto-Lei n. ${ }^{\circ}$ 176/2006, de 30 de agosto. Portugal. [citado em 5.fev.2021]. Disponível em:

http://www.pgdlisboa.pt/leis/lei mostra articulado.php?nid=1884\&tabela=leis

16. Portugal. Decreto-Lei n. ${ }^{\circ}$ 97/2015, de 1 de junho. Portugal. [citado em 5.fev.2021]. Disponível em:

http://www.pgdlisboa.pt/leis/lei mostra articulado.php?artigo id=2354A0039\&nid=2354\&ta bela=leis\&pagina $=1 \&$ ficha $=1 \&$ nversao $=$

17. Ascensão JO. O projecto de Código da Propriedade Industrial: patentes, modelos de utilidade e modelos e desenhos industriais. Revista da Faculdade de Direito da Universidade de Lisboa, vol. XXXVIII - n. ${ }^{\circ}$ 1. Lisboa: Coimbra Editora; 1997. p. 161.

18. Genebra. Organização Mundial do Comércio (OMC). Trade-Related Aspects of Intellectual Property Rights (TRIPS). [citado em 10.fev.2021]. Disponível em: https://www.wto.org/english/tratop e/trips e/trips e.htm

19. Montaña M. Was the recent skirmish on the TRIPS Agreement and Covid-19 really worth it? [Internet]. Kluwer Patent Blog. 2020 [citado em 27.out.2020]. Disponível em: http://patentblog.kluweriplaw.com/2020/10/26/was-the-recent-skirmish-on-the-tripsagreement-and-covid-19-really-worth-it/

20. Genebra. Organização Mundial do Comércio (OMC). Declaration on the TRIPS agreement and public health. [citado em 28.mai.2021]. Disponível em:

https://www.wto.org/english/thewto e/minist e/min01 e/mindecl trips e.htm 
21. Genebra. Organização Mundial do Comércio (OMC). Guide to Notifications. [citado em 28.mai.2021]. Disponível em:

https://www.wto.org/english/tratop e/trips e/par6 modelnotifs e.htm

22. União Europeia. Regulamento (CE) n. ${ }^{\circ} 816 / 2006$ do Parlamento Europeu e do Conselho, de 17 de Maio de 2006. [citado em 7.fev.2021]. Disponível em: https://eurlex.europa.eu/legal-content/PT/TXT/?uri=CELEX\%3A32006R0816

23. Marques JP. Remédio. São os direitos de propriedade industrial úteis para a nossa saúde? A articulação entre o direito de patente e a regulação farmacêutica perante epidemais e as pandemais. Revista de Direito Intelectual, n. ${ }^{\circ}$ 2. Coimbra: Almedina; 2020.

24. Marques JP. Remédio, Licenças (Voluntárias e Obrigatórias de Direitos de Propriedade Industrial). Coimbra: Almedina; 2008. p. 19.

25. Genebra. Organização Mundial do Comérico (OMC). Guide to Notifications. [citado em 28.mai.2021]. Disponível em:

https://www.wto.org/english/tratop e/trips e/par6 modelnotifs e.htm

25. Musmann T. Update on Patent-Related measures in Germany in View of corona Pandemic [Internet]. Kluwer Patent Blog; 2020 [citado em 02.abr.2020]. Disponível em: http://patentblog.kluweriplaw.com/2020/04/02/update-on-patent-related-measures-ingermany-in-view-of-corona-pandemic/

26. França. Code de la defense. [citado em 02.fev.2021]. Disponível em: https://www.legifrance.gouv.fr/codes/id/LEGITEXT000006071307/

27. Pochart F, La Verteville OM, Rauline M. Licences d'office: une application dans la crise du Covid-19 en France? [Internet]. [citado em 05.mai.2020]. Disponível em:

https://www.august-debouzy.com/fr/blog/1538-licences-doffice-une-application-dans-lacrise-du-covid-19-en-france

28. Canada. Statutes of Canada 2020, Chapter 5, An Act respecting certain measures in response to COVID-19. [citado em 02.fev.2021]. Disponível em:

https://www.parl.ca/DocumentViewer/en/43-1/bill/C-13/royal-assent 